\title{
A comparison between \\ ultralow-frequency ballistocardiograms and those secured by an improved high-frequency technique, with studies to explain remaining differences
}

\author{
Isaac Starr, M.D. \\ Philadelphia, Pa. \\ Abraham Noordergraaf, Ph.D. \\ Utrecht, Netherlands
}

$\mathrm{T}$ The advance in ballistocardiographic instrumentation which has been so rapid and so encouraging in recent years has been due primarily to the use of certain physical principles. On the assumption that well-known physical formulae could be properly applied to the vibration problems of the human body, a new viewpoint emerged. This included a well-based criticism of the high-frequency ( $\mathrm{HF}$ ) ballistocardiograph, ${ }^{1,2}$ i.e., that the movement which took place between body and table was introducing an error, and that the vibration properties of this movement between body and table led to an undue magnification of certain components of the recorded forces, those delivered in resonance with the body's own vibration properties, and undue attenuation of others, those above the body's resonance frequency. It was proposed $t o$ avoid or minimize such errors by using another type of instrument, the ultralow-frequency (ULF) ballistocardiograph..$^{3-6}$

The very considerable technical problems were overcome in a number of laboratories, and several types of excellent ultralow- frequency ballistocardiographs have been constructed; these differ only in technical details and give essentially similar records. With this experience before us the instrument used in this study was constructed by Mr. George Peirce.

The possession of such an instrument permitted us to compare force ballistocardiograms taken by the ultralow-frequency technique, when acceleration of the table is recorded, with force ballistocardiograms taken with the high-frequency technique, when displacement of the table is recorded. We expected that a study of the differences between the two force records would provide important information, because each instrument approached the problem from a different direction, and neither method seemed altogether free of error. Thus, if the records secured by each inethod closely agreed with one another, we would have strong evidence that the remaining errors were not important.

In addition, by testing large numbers of healthy persons and patients by both methods, we could not only compare and define their comparative utility in the

From the Department of Therapeutic Research, Univer sity of Pennsylvania, Philadelphia, Pa., and the Department of Medical Physics, Physical Laboratory, University of Utrecht, Utrecht, Netherlands.

This work was supported by Research Grant H-625 (C-8,9,10) from the National Heart Institute, National Institutes of Health, United States Public Health Service.

Received for publication Nov. 17, 1961 . 


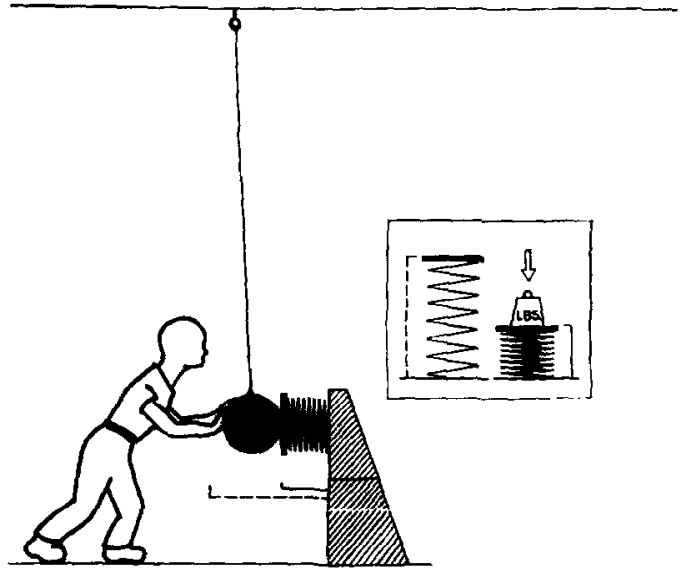

Force-Displacement of a fixed spring (High frequency ballisto)

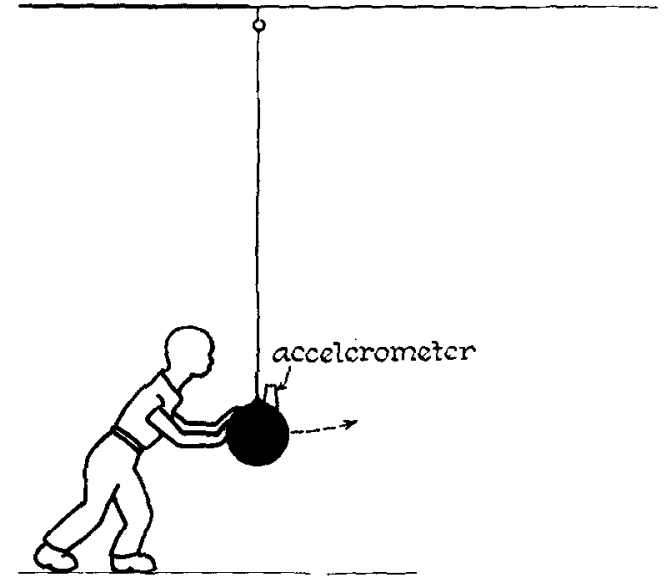

Force $=$ Mass $\times$ acceleration of an object free to move (Ultra low-Frequency ballisto)

Fig. 1. Illustrations of the principles behind HF and ULF ballistocardiographs. Our problem is to measure the force with which the little man pushes on the ball suspended by a very long and light wire. In the first method we place a strong spring behind the ball. When the little man pushes the ball, this spring is compressed a short distance which we can measure (displacement measurement). Then, after turning the spring upright, we add weights until the spring is compressed the same distance. So we compare the unknown force with a known force. In the second method we leave the suspended ball as free to move as is possible. Now, when the little man pushes, the ball is accelerated. An instrument mounted on the ball records the amount of acceleration. The force applied can be calculated from the product of the acceleration recorded and the mass moved, i.e., the total mass of ball and accelerometer. Of course, the little man of this figure applies a force external to the ball, whereas the ballistocardiogram comes from forces having their origin within the body. detection of cardiovascular abnormality, but also investigate the matter from a practical point of view, by asking the question, "Does ultralow-frequency ballistocardiography provide a better clinical method than the high-frequency technique?" Accordingly, during the past years we have tested over 400 patients and healthy persons by both methods; the second test was made as soon as the first was completed. An explanation of the differences between the records secured by the two instruments was sought by mathematical studies and by several series of experiments.

\section{Theory}

When one is interested in the forces, the theory behind the two types of ballistocardiographs can be easily grasped by reference to Fig. 1, which is designed to demonstrate the two different ways of measuring an unknown external force. In ballistocardiography, one is interested in the internal force, or what is proportional to such force, the acceleration of the body's center of gravity, and the same two methods can be used to detect it.

\section{Instruments}

The ultralow-frequency ballistocardiograph. The bed, made of a frame of hard aluminum alloy (61 ST 1) tubing, supporting a hammock of Grade A airplane fabric, was constructed for us by the late Dr. M. B. Rappaport, and was essentially similar to that which he has described. ${ }^{6}$ After we had added a footplate, magnets, and fittings, the total weight was 3.3 kilograms. The general setup is shown in Fig. 2; the mass and physical properties are given in Table I.

Unlike that illustrated in Rappaport's article, ${ }^{6}$ our bed was suspended from the ceiling by four wires, each $182 \mathrm{~cm}$. in length. Because our room had a low ceiling, our bed-like Rappaport's instrument, and like Henderson's lable of 50 years agois displaced laterally by a pair of pins ( $A C$, lig. 3), sharp at each end and 13.7 $\mathrm{cm}$. long. When these pins are in place, the point of support of the suspension on this same side is not directly over the end of the pin $(A)$, but over a point $(B) 1.5 \mathrm{~cm}$. from this base. The natural frequency of 
Table I. Physical properties of our new $H F$ and ULF tables, without a subject

\begin{tabular}{|c|c|c|}
\hline & $\begin{array}{c}H F \\
\text { table }\end{array}$ & $\begin{array}{l}\text { ULF } \\
\text { table }\end{array}$ \\
\hline Mass (Kg.) & 36 & 3.3 \\
\hline $\begin{array}{l}\text { Resonance frequency when } \\
\text { loaded with } 74-\mathrm{Kg} \text {. iron } \\
\text { bars (cycles/sec.) } \\
\text { Damping ( } \% \text { of critical valuc) }\end{array}$ & $\begin{array}{r}12.7 \\
5.0\end{array}$ & $\begin{array}{l}0.12 \\
10\end{array}$ \\
\hline
\end{tabular}

Table 1I. Masses which move with the $\mathrm{HF}$ table, not including the subject

Table top and footplate

Aluminum bracing

$23 \mathrm{Kg}$.

Picker Flexicast for shoulder yoke

Picker Flexicast for small of back

Nonslip pad

10

1.4

$36 \mathrm{Kg}$.

the system is about 0.12 cycles per second, a value which varies a little with differences in the stretch in the support wires caused by differences in the weights of the patients. No mechanism to provide additional damping has been used.

The electrical apparatus used is identical to that described by Rappaport, except that we use two bar magnets and two coils. The corresponding poles of the magnets are placed in opposite directions, so that the signal adds but the interference substracts. The resulting voltage is fed into circuits, described by Rappaport, ${ }^{6}$ capable of integrating and differentiating it, but we have used only the differentiating circuit in this investigation. A record of acceleration was secured by means of the amplifier and recorder of a Sanborn TwinViso instrument. Up to this point, our equipment is only slightly modified from that described by Rappaport.

Because the coils are supported from the floor, we found it very difficult to get the record sufficiently free of building vibrations. After much experimentation we now use the following arrangement. Three small wooden pieces in contact with the floor support a $100-\mathrm{Kg}$. concrete block. Above this block is a wooden board the position of which can be adjusted by three screws. On this board lie a $15-\mathrm{cm}$. thickness of folded nylon blankets and another board on which the coils rest. This system renders our records almost altogether free of building vibration.

Of great value has been a secondary electrical circuit, with dry cells and a milliammeter, which indicates when one of the magnets touches the inside of its coil, an error of technique very likely to pass unnoticed without this warning device, and capable of causing marked distortion of the ballistocardiogram.

We use a calibrator designed by Dr. Walter Gamble. ${ }^{16}$ Two forces, each of $140 \mathrm{Gm}$., one directed headward, the other footward, are allowed to act alternately on the table by a pendulum that interrupts first one and then the other.

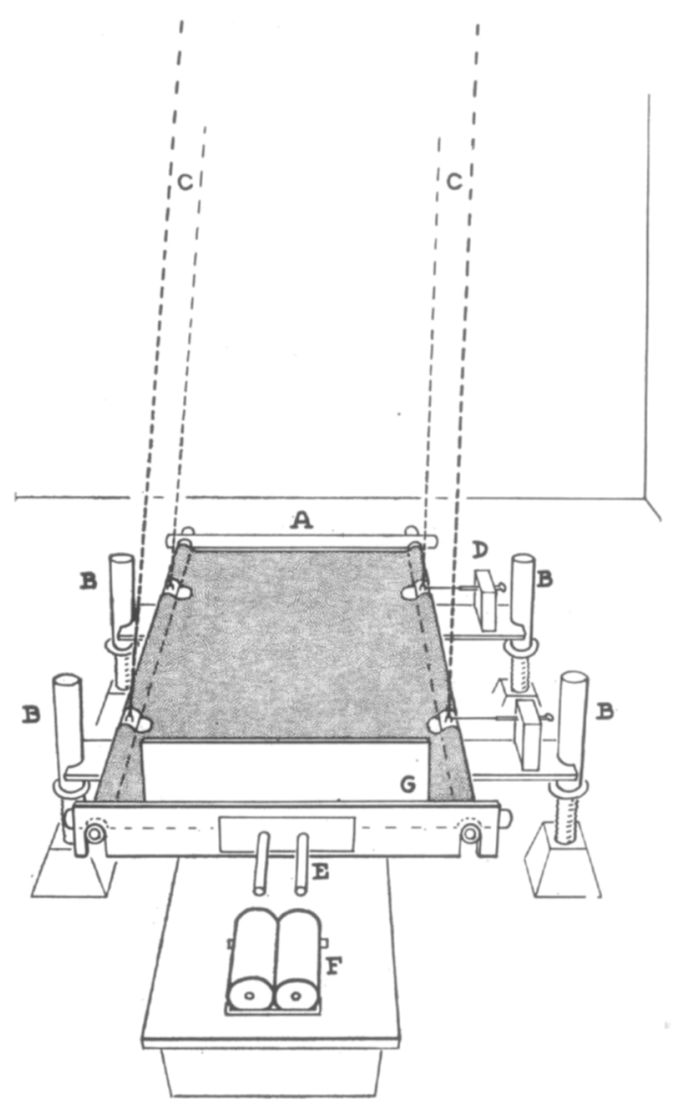

Fig. 2. Our II F ballistocardiograph. $A$, The table. $B$, "Mine jacks," columns of heavy pipe extending between floor and ceiling to support the frame from which the table is suspended. Only the base is shown in the figure. $C$, Support wires. $D$, Lateral support. $F$, Coils shown withdrawn from magnets E. $G$, Footboard. 


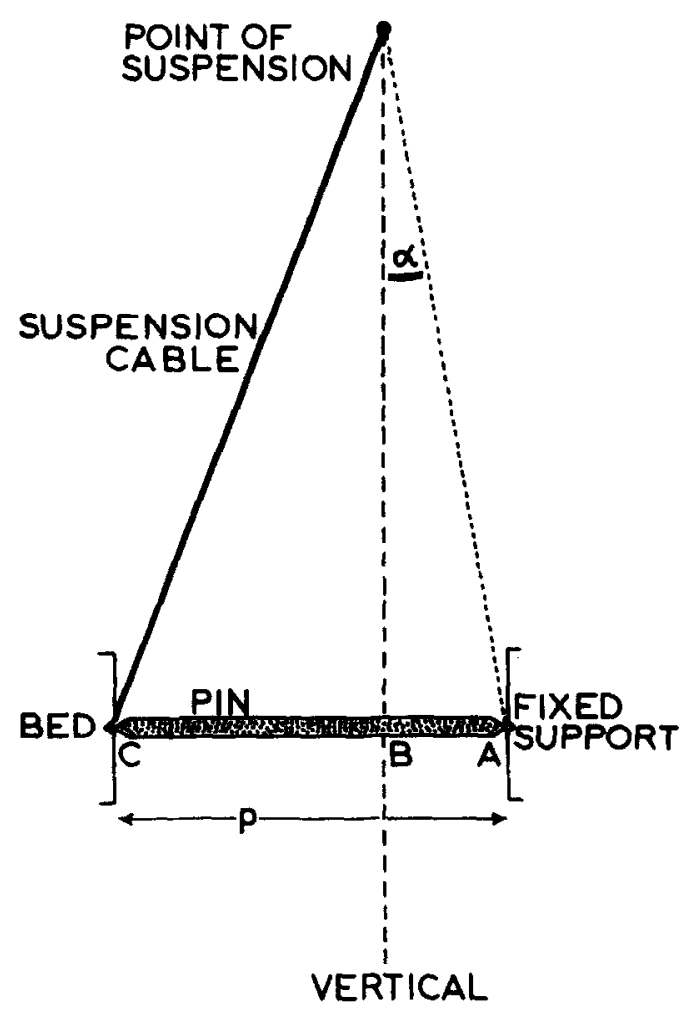

Fig. 3. Diagram which shows details of the suspension of our ULF instrument. To conserve space, the vertical dimension has been reduced in respect to the horizontal. $A B=1.5 \mathrm{~cm}$.; angle $\alpha=0.5$ degrees.
This produces a series of square waves of about 0.4 second duration in the base line of the record. By this means the height of any wave of the ballistocardiogram can be related to the forces applied.

The newest high-frequency instrument. The design of our latest instrument stemmed from the desire to take ballistocardiograms with the subject tilted as well as horizontal. This instrument, made for us by the Technitrol Engineering Company, is shown and briefly described in Fig. 4. The masses and vibration properties are given in Tables I and II.

From the first, our standard technique of getting the subject tight on the table has been to have him lie on it with his feet in contact with the footplate and his knees bent. Then, by straightening his knees the body was forced headward, putting tension on the clothing and skin of his back as well as increasing the pressure of his heels on the footplate.

This technique has been improved as follows. A pad of thin rubber-like material, ordinarily used to prevent small rugs from slipping on a polished floor, has been placed on the table top; this has proved to be an important addition when the table

Table III. Effect of tighlening the subject on the HF table. The frequency and damping of movement between subject and table under various conditions

\begin{tabular}{|c|c|c|c|}
\hline Subject & Conditions & $\begin{array}{l}\text { Frequency } \\
\text { (c.p.s.) }\end{array}$ & $\begin{array}{l}\text { Damping } \\
\text { as defined } \\
\text { by } x_{2} / x_{1}\end{array}$ \\
\hline \multirow{3}{*}{$\begin{array}{l}\text { J.U. } \\
\text { (mass } 85 \mathrm{Kg} \text { ) }\end{array}$} & Lying on nonslip pad, feet free of footplate & 5.8 & 0.60 \\
\hline & On nonslip pad, feet against foot plate & 8.1 & 0.52 \\
\hline & $\begin{array}{l}\text { On nonslip pad, tight between Flexicast shoulder yoke and } \\
\text { footplate }\end{array}$ & 7.6 & 0.28 \\
\hline \multirow[t]{5}{*}{$\begin{array}{l}\text { F.X.E. } \\
\text { (mass } 66 \mathrm{Kg} . \text { ) }\end{array}$} & Lving on bare table feet free of footplate & 5.4 & 0.41 \\
\hline & Lying on nonslip pad, feet free of footplate & 5.0 & 0.51 \\
\hline & Lying on nonslip pad, feet tight against footplate & 7.1 & 0.35 \\
\hline & On pad, tight between Flexicast shoulder yoke and footplate & 7.2 & 0.33 \\
\hline & Same, but tighter & 8.2 & 0.68 \\
\hline \multirow{5}{*}{$\begin{array}{l}\text { B.P. } \\
\text { (mass } 72 \mathrm{Kg} \text { ) }\end{array}$} & & & \\
\hline & $\begin{array}{l}\text { Hilted } 15 \text { degrees } \\
\text { tilte }\end{array}$ & 7.2 & 0.34 \\
\hline & Same, level & 7.0 & 0.72 \\
\hline & Same, Flexicast soft & 6.8 & 0.52 \\
\hline & Lying loose on table, feet free of footplate & 5.0 & 0.48 \\
\hline
\end{tabular}


top is of polished metal as in our newer instruments. Also, we have used a patented device sold by the Picker X-ray Company under the name of Flexicast, and designed originally for the purpose of fixing various parts of the body for $x$-ray therapy. It is a kidney-shaped bag of rubber filled with a granular substance which is easily moulded at atmospheric pressure, but which, when air is pumped out of the bag, becomes stony hard. Two perforated aluminum tubes attached to the table footplate, and a movable crosspiece held in place by pins through each tube, serve to fix the Flexicast in position. For a while, we also used a small bag of Flexicast under the small of the back, but recently we have discarded it.

Therefore, in our latest technique the subject lies on the table on top of the nonslip pad with his feet on the footplate and his knees flexed. The Flexicast, while soft, is moulded around his neck and shoulders and held in place by the crosspiece adjusted to the length of the subject. The Flexicast is then hardened by connection to the vacuum line of the building. Then the subject, by straightening his knees, compresses himself between footplate and the shoulder yoke of the Flexicast.

By this technique the force of compression can be made as great as any subject can stand; we have used forces as high as 70 kilograms. But too much compression is painful; it also tends to arch the back and so may defeat its purpose of tightening the subject on the table by diminishing the area of contact. Also, anything which causes discomfort may defeat our purpose by altering the circulatory forces that we are measuring. Hence, we aim at the tightest attachment consistent with complete comfort and adjust the position of the crosspiece until this is obtained.

Theoretical comparison of the high-frequency and ultralow-frequency instruments. The physical properties of the two instruments are given in Table $\mathrm{I}$.

One also needs to know the physical properties of the attachment of the subject's body to the tables. The latter data were found by experiments conducted on 3 healthy subjects as follows.

The table of the high-frequency instru- ment was clamped to the frame, and the subjects lay on it with a light bar strapped to their shins. A screen attached to this shin bar partly interrupted a light beam playing on a phototube; both light source and phototube were attached to the table. ${ }^{7}$
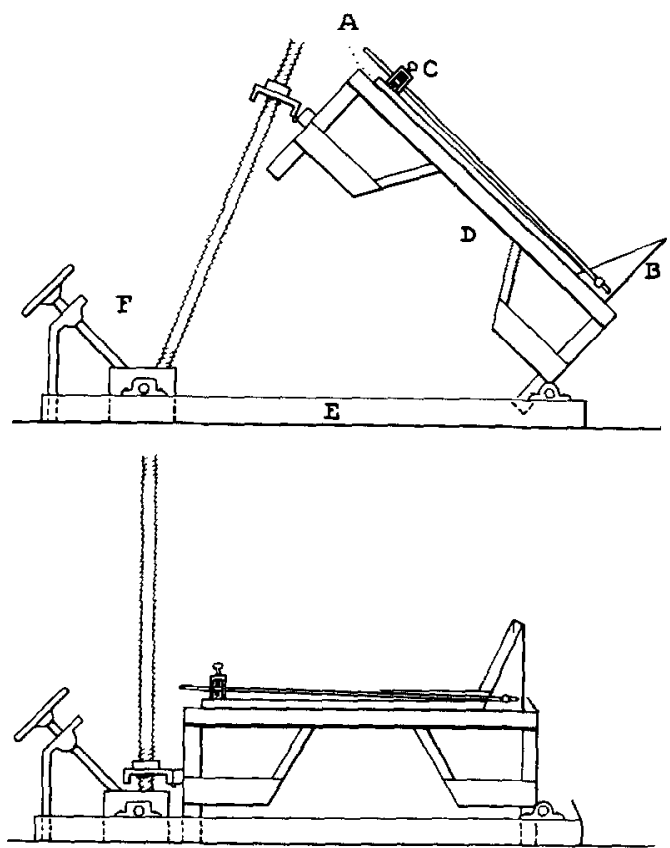

Fig. 4. Our newest $H F$ ballistocardiograph, shown tilted, and in the horizontal position in which it is usually employed. $A$, The table. Neither the $5-\mathrm{cm}$. suspension nor the strong restraining spring is shown. The table is made of 24 st aluminum, and with the footplate and braring weighs 24 kilograms. $B$, The footplate. $C$, Movable crosspiece and pipes which attach it to footplate, used to support the shoulder yoke. $D$, Main table frame of cold rolled steel, weighing 110 kilograms. $E$, Base frame of cold rolled steel, also weighing 110 kilograms, $F$, The lifting mechanism, which weighs about 90 kilograms. Between base frame and floor are 4 pads of corrugated rubber and 2 of cork, each about 7 by $7 \mathrm{~cm}$. and $7 \mathrm{~mm}$. thick.

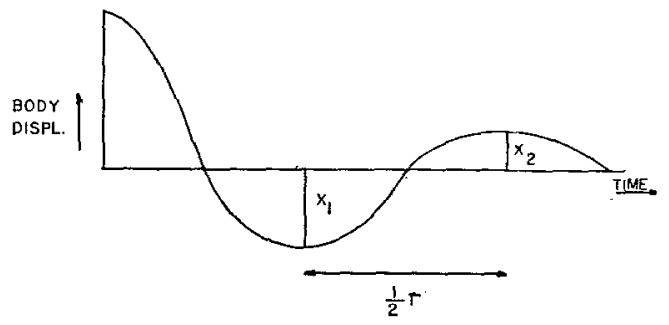

Fig. 5. Diagram of the movement of the body on a $\mathrm{HF}$ table, or on any other immobile surface, when a force applied headward or footward is suddenly released. 


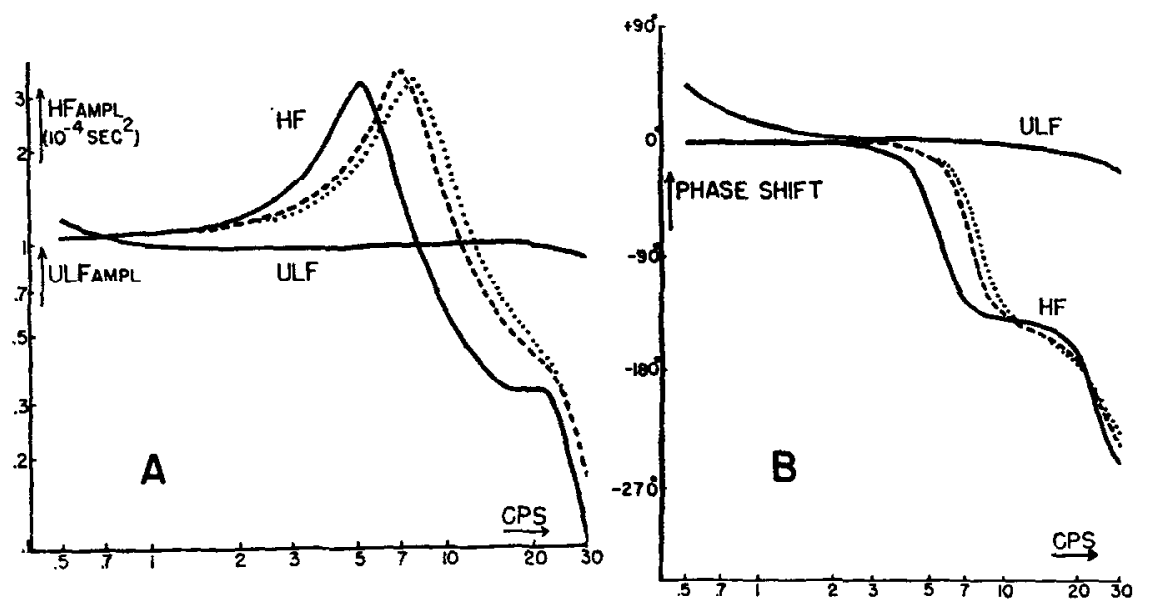

Fig. 6. $A$, Amplitude characteristics of the HF and ULF ballistocardiographs. The former were calculated for various degrees of tightening of the subject to the HF table, using the top and bottom lines of Table IV. Solid line: Subject loose. Dashed line: Subject tight. Dotted line: Subject very tight. The last is defined by a damping coefficient of $25 \times 10^{5} \mathrm{Gin}_{\text {.sec. }}{ }^{-1}$ and a restoring force of $24 \times 10^{7} \mathrm{Gm} . \mathrm{sec}^{-2}$. $B$, Phase characteristics for the same cases.

Table IV. Average values and standard deviations for restoring force and damping as the 3 subjects were tightened on our HF table

\section{Conditions}

Loose, feet off footplate

Nonslip pad on table top, feet firm against footplate, back tightened by forcing it headward on nonslip pad

Nonslip pad on table top, Flexicast hardened to form shoulder yoke, body compressed between yoke and footplate

Nonslip pad on table top, hardened Flexicast supported by aluminum bracing, body compressed between yoke and footplate

Damping
coeffrient
$\left(10^{5} \mathrm{Gm} . \mathrm{sec} .^{-1}\right)$

$11 \pm 1$

19

21

$18 \pm 5$
Restoring

force

$\left(10^{7} \mathrm{Gm} . ~ s e c .^{-2}\right)$
The gain was reduced until the ballistocardiogram was scarcely visible; then the subject was given a push, either headward or footward, and suddenly released. The record after such release was that of a damped vibration, of the type shown in Fig. 5. Experiments of this type were conducted when the subjects were lying loose on the table and after various means had been taken to tighten them to it.

On the assumption that the body moves as a unit, the physical characteristics of the coupling between body and table can be calculated from the duration of the cycle and the ratio of the successive amplitudes, such as is shown in Fig. 5. The results are given in Table III.
In addition, from the data secured in Table III, from other data of the same type, and by making use of the constants and methods described, ${ }^{5}$ we calculated the value for the damping and restoring force of the coupling between subject and table top. The average values secured for subjects lying loose on the table and after the application of various means of tightening them to it are given in Table IV. By our methods of tightening the subject the restoring force and damping are about doubled. The nonslip pad contributes a great deal to the sucress of the technique; without it the body slips badly on the polished metal of the table surface. The Flexicast yoke contributes something more, 
but not very much, and its weight is a disadvantage.

The calculated amplitude and phase characteristics of the two instruments can be compared in Fig. 6 .

\section{Results}

Comparison of the ULF and $H F$ force records in healthy persons. Ballistocardiograms were taken by both instruments, each with a simultaneous electrocardiogram, on 30 healthy men and 20 healthy women, drawn from the faculty and students of the medical school, from personnel working in the hospital, and from a group of professional athletes who were soon to enter a long-distance swimming contest. The first test was made after the subjects had rested for 15 minutes or longer; they then walked about 20 steps to the other instrument, and the second test followed after another 15 minutes of rest. A calibration was made at the time each record was taken.

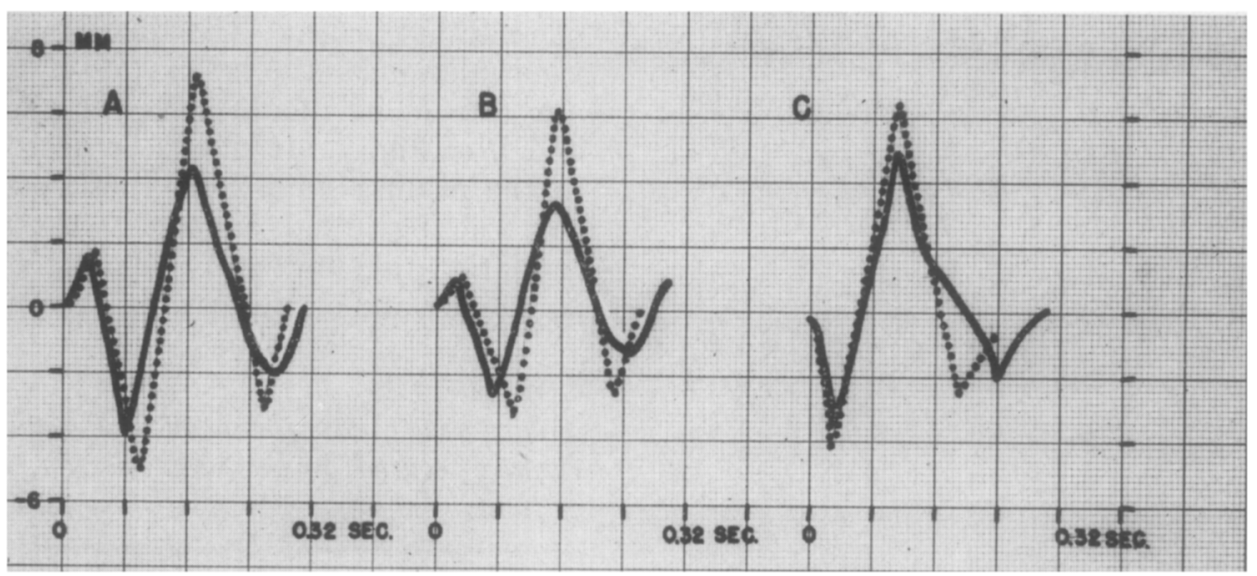

Fig. 7. Average difference in timing and amplitude of recorded force between the general wave form and the ULF and HF ballistocardiograms of healthy young adults. $A$, Comparison between average HF (dotted line) and ULF (solid line) ballistocardiograms of men. The time relationship between both curves was derived from simultaneously recorded electrocardiograms. $B$, Same as $A$, for women. $C$, Difference between the force applied to the head of a cadaver (solid line) and the resulting $\mathrm{HF}$ ballistocardiogram (dotted line) (redrawn from a previous publication ${ }^{1}$ ). The data secured in this early experiment do not permit accurate placing of the two curves relative to one another in time, and they have been placed here with the $I$ and $J$ tips aligned in time. If the dotted curve is placed a little later in time, the resemblance of $C$ and $A$ is evcn more striking. The calibration of the vertical coordinate: $10 \mathrm{~mm} .=280 \mathrm{Gm} .=27+\times 10^{3}$ dynes.

Table V. Averages of the differences found between the four main systolic waves of ULF and HF ballistocardiograms in 30 healthy men and 20 healthy women

\begin{tabular}{|c|c|c|c|c|c|c|}
\hline & \multicolumn{2}{|c|}{$\begin{array}{c}\text { Differences in amplitude } \\
(\mathrm{mm} .) \\
(w h e n 10 \mathrm{~mm} .=280 \mathrm{Gm} .)\end{array}$} & \multicolumn{2}{|c|}{$\begin{array}{l}\text { Differences in duration } \\
\qquad(\mathrm{sec})\end{array}$} & \multicolumn{2}{|c|}{$\begin{array}{l}\text { Differences in area } \\
\quad(\text { mm. sec. })\end{array}$} \\
\hline & Mean & $\sigma$ & Mean & $\sigma$ & Mean & $\sigma$ \\
\hline H wave & -0.13 & 0.78 & -0.0046 & 0.019 & -0.003 & 0.03 \\
\hline I wave & $+0.77^{*}$ & 1.18 & $+0.0065^{*}$ & 0.013 & $+0.040^{*}$ & 0.05 \\
\hline J wave & $+2.48^{*}$ & 1.74 & $-0.035^{*}$ & 0.02 & $+0.033^{*}$ & 0.10 \\
\hline $\mathrm{K}$ wave & $+1.25^{*}$ & 1.20 & +0.029 & 0.03 & $+0.049^{*}$ & 0.09 \\
\hline
\end{tabular}




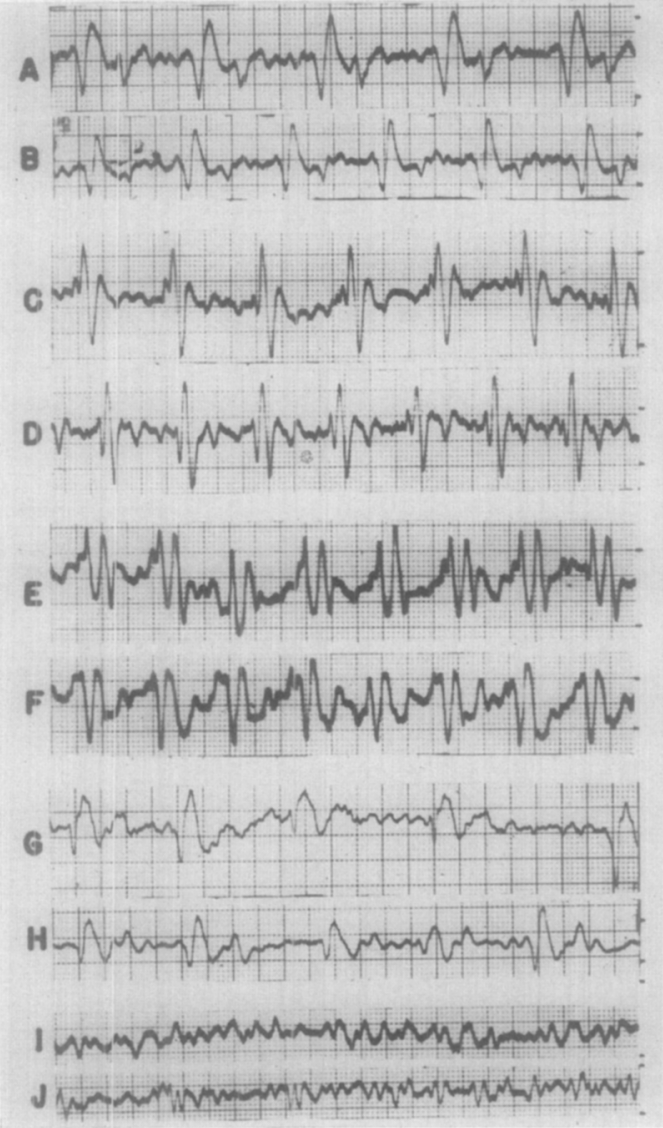

Fig. 8. Comparison of ULF and HF ballistocardiograms. A series arranged to show how similar the two types of records often are. The dots on the right margin indicate a calibration of $280 \mathrm{Gm}$. Note that the ULF calibration is usually larger than the $\mathrm{HF}$ one. ULF $(A)$ and $\mathrm{HF}(B)$ records of T.P., a 25 -year-old normal male medical student. $C$ and $D$, Records of C.W., a 53-year-old woman with postural hypotension. $E$ and $F$, Records of P.E., a 45-year-old woman with hyperthyroidism. $G$ and $H$, Records of W.R., a 49-year-old man with hyperthyroidism and auricular fibrillation. $I$ and $J$, Records of S.P., a 55-year-old woman with organic heart disease which was believed to be congenital in origin, possibly atrial septal defect. The reproduction is one half the size of the original records.

In the measurement of the records, typical large and small complexes of the respiratory cycle were selected; in each the amplitude of the $\mathrm{H}, \mathrm{I}, \mathrm{J}$, and $\mathrm{K}$ waves from the base line of the record and the duration of each wave on this base line were measured. From the mean of the values obtained from the large and small complexes of the respiratory cycle of each subject, an average ballistocardiogram was constructed for that subject.

The measurements secured in the 30 men were used to construct a grand average normal male ballistocardiogram of the HF type, and another of the ULF type. Similar grand average normal female ballistocardiograms were also constructed. Knowledge of the time which elapsed between the tip of the $R$ wave of the electrocardiogram and the peak of each wave of the $\mathrm{HF}$ and ULF ballistocardiograms permitted us to place the average $\mathrm{HF}$ and ULF records in the proper relation to one another in time. The time and amplitude relation of the two types of records are shown in quantitative terms in $A$ and $B$ of Fig. 7. It should be noted that, in the result obtained by this method of constructing grand averages, detailed information about small differences, such as notches and slurs, does not appear.

Table VI. Comparison of HF and ULF records secured on the same person, in 250 patients

Per cent

HF and ULF have only their "usual" differences 60

ULF shows a notch which HF shows less clearly or not at all

ULF shows an I wave when I wave of $\mathrm{HF}$ is absent

Resonance in HF, none in ULF

Fine vibrations disturb ULF; not IIF

Fine vibrations disturb HF; not ULF

Artifacts in ULF (coils touching magnets?)

Other differences

2

1

5

2

3 2

Table VII. Comparison of the clinical interpretation given to $H F$ and ULF records secured on the same person, in 250 patients

Per cent

Both records given the same interpretation

ULF suggests greater cardiac abnormality than $\mathrm{HF}$

HF suggests greater cardiac abnormality than ULF 


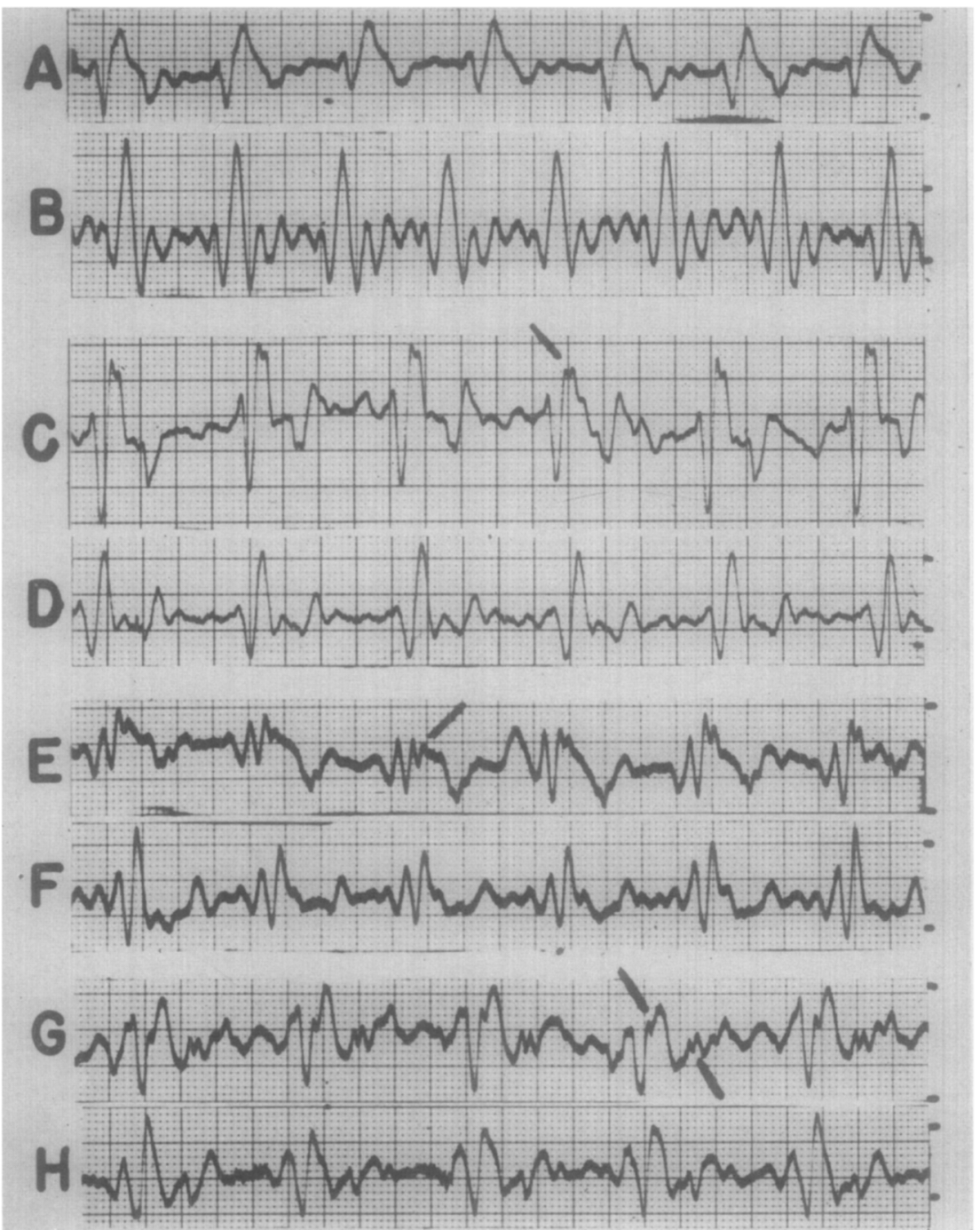

Fig. 9. Comparison of ULF and HF ballistocardiograms. A series arranged to show the common differences encountered in the two types of records. Lines point to features of interest. The ULF record is above the HF record of each subject. $A$ and $B$, Records of J.H., 15 years old, complaining of nervousness; nothing else abnormal was discovered. Note striking difference between ULF and HF records. The form of the $\mathrm{HF}$ record indicates that the subject was not fastened tightly to the instrument and there has been an error in technique. $C$ and $D$, Records of J.H., a normal 23-year-old man. Note notching of the tip of the $\mathrm{J}$ wave in the ULF, but not in the HF record. Note other notches in ULF record not seen in HF record. $E$ and $F$, Records of K.E., a healthy 54-year-old man. Blood pressure of $125 / 85 \mathrm{~mm}$. Hg. Note the flat, deeply notched $J$ wave of the ULF record which looks abnormal, whereas the IIF record looks altogether normal. Note also that notches of the same frequency as that of the $J$ wave are to be seen in other places in the ULF record. $G$ and $H$, Records of I. H., a normal 41-year-old man. Blood pressure of $120 / 80 \mathrm{~mm}$. Hg. Note the notch in the I-J segment of the ULF record not shown in the HF record. Note also notches of similar frequency in the L-M-N complex of the ULF record. These notches do not appear in the HF record. The reproduction is four fifths the size of the orig. inal records. 


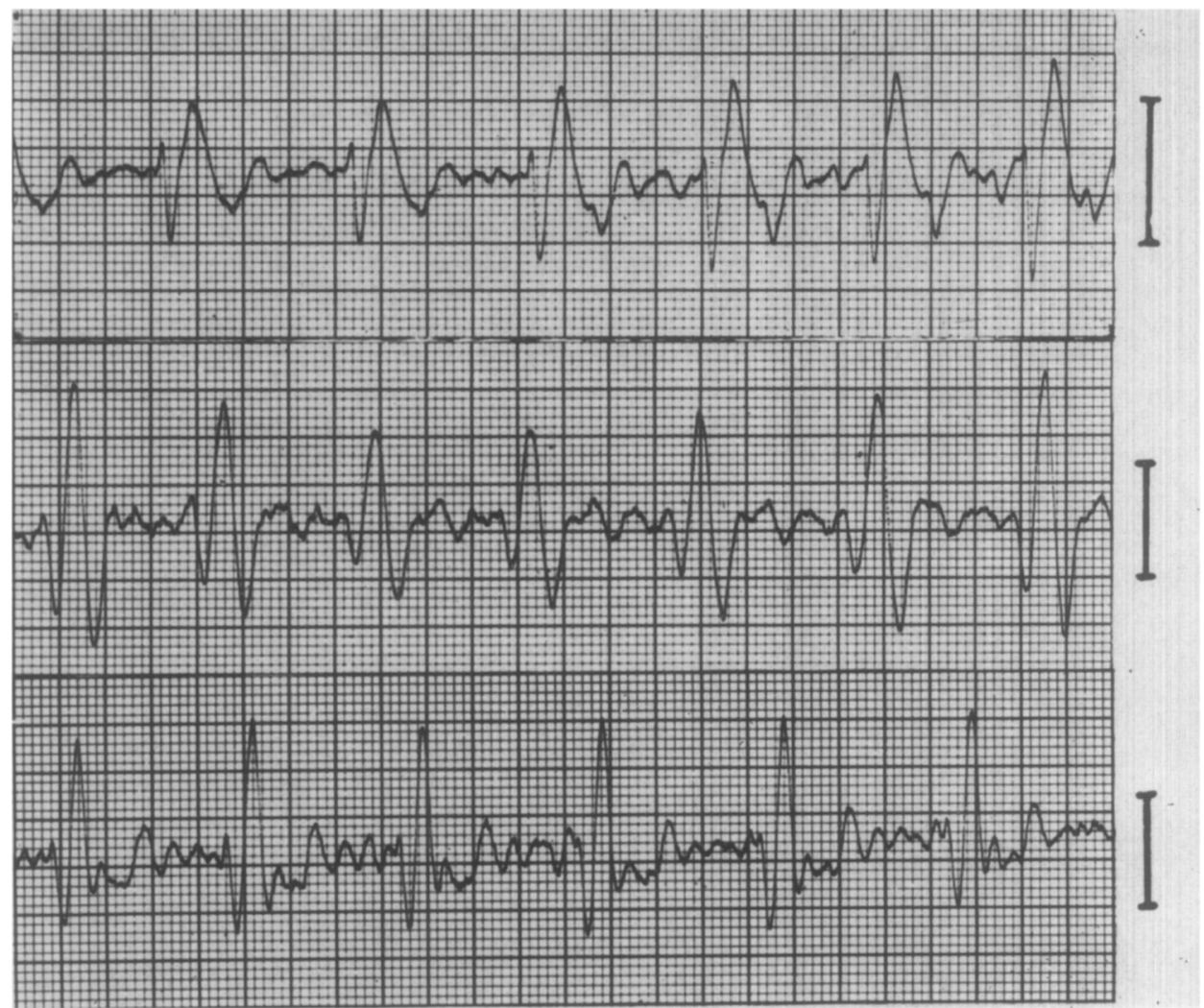

Fig. 10. Experimental $\left[\mathrm{ILF}^{\mathrm{i}}(\right.$ tOD) and $\mathrm{HF}$ ballistocardiograms (subject loose, middle; subject tight, bottom) of Subject B.P. The vertical lines in the right margin show a calibration of $274 \times$ $10^{3}$ dynes. The reproduction is the size of the original.

The results of the statistical analysis, made by the method of paired experiments, are given in Table $V$. The $H$ waves of the two records are essentially identical in height and area; the I wave of the $\mathrm{HF}$ record tends to be a little deeper $(t=4.1)$ and a barely detectable amount broader $(\iota=3.1)$ than that of the ULF record; the average $J$ wave of the $H F$ record is much taller $(t=8.8)$ and much narrower $(t=11.2)$ than that of the ULF record. Despite this difference in shape the average $\mathrm{J}$-wave areas are so very nearly similar in the two types of records that the significance of the difference was just demonstrated, $\mathrm{l}=2.2$. The amplitude and area of the $K$ wave are significantly larger in the HF records.

The tips of the $\mathrm{H}$ and $\mathrm{I}$ waves of the HF records follow those of the ULF records by an average of 0.012 and 0.022 second, respectively, and these are significant differences. The average differences between the timing of the tips of the $J$ and $K$ waves are still smaller and not statistically significant in our small series.

Comparison of ULF and HF records secured in patients with and without cardiovascular disease. The experience with patients is summarized in Figs. 8 and 9 and Tables VI and VII. Thus, Fig. 8 is designed to illustrate the many instances in which ULF and HF records resemble each other closely. In contrast, Fig. 9 illustrates the differences most commonly encountered. In Table VI, the experience with the two types of records is compared. In Table VII, the senior author has compared his interpretation of the two records in terms of cardiac function.

The differences which are found between HF and ULF records taken on the same patient can be classified into three groups. In the first group are the differences in size and shape of the waves. Thus, in the patients, as in the healthy persons, the J 
wave of ULF records tends to be shorter and broader than that of $\mathrm{HF}$ records. Also the ULF $\mathrm{K}$ wave is usually shorter than that of the $\mathrm{HF}$ record.

The differences of the second group manifest themselves as notches, divided waves, and slurs. Examples of these can be clearly seen in Fig. 9. Almost without exception these extra waves are seen in the ULF record, and they are absent or less well shown by the HF record.

The differences of the third group are more diverse for they comprise all those not included in the first two groups. Some are most certainly due to artifacts from building vibrations, to which both instruments are subject at times, whereas others appear to be artifacts from contact between the moving table and some stationary object. Occasionally, an unexplained difference is found between the two records, and one must recall that the diseased heart is more variable in its performance from minute to minute than is the normal heart, and that our HF and ULF records were not taken simultaneously but about 20 minutes apart. Thus, the differences in this diverse third group are due chiefly to the common accidents and artifacts that occur in taking ballistocardiograms; they will not be discussed further.

Analysis of the differences between the two force records. We first asked ourselves whether differences in the physical properties of the two setups would explain the differences found between their records. If this were true, we should be able to start with the record secured by one instrument and, through the use of physical principles, compute the record of the other. The mathematics involved in such a computation, although complex, have long been known, but until recently such work has been so laborious that the practical application of these methods to a problem such as this has been impossible. It became possible only recently with the development of the digital computer. Accordingly, the problem was attacked by means of a Fourier analysis of the records of 2 healthy subjects (B.P. and F.Y.E.), using the Univac computer at the University of Pennsylvania.

We took as a starting point a typical complex secured by the low-frequency instrument, a complex midway between the largest and smallest ones of the respiratory cycle. The complex chosen for

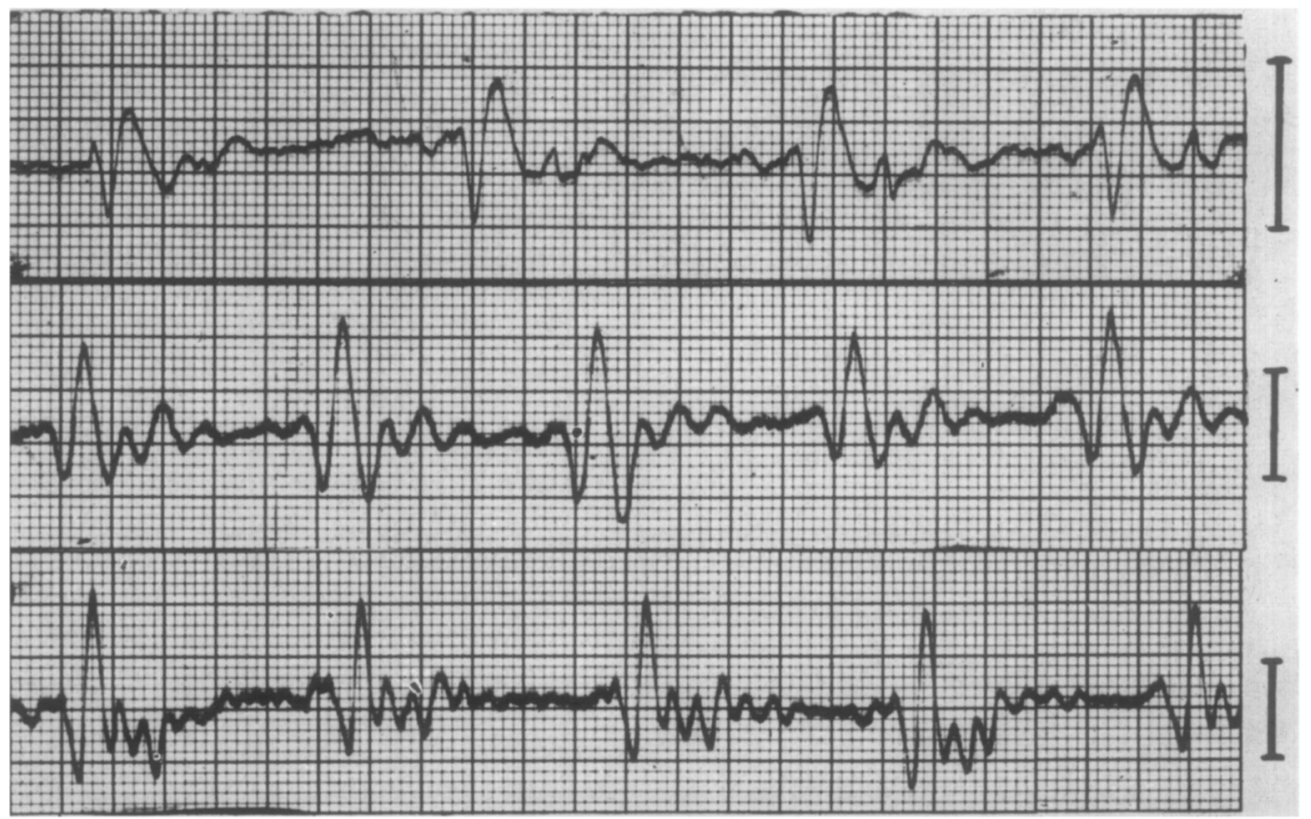

Fig. 11. Experimental ULF (top) and HF ballistocardiograms (subject loose, middle; subject tight, bottom) of Subject F.Y.E. Calibration of $274 \times 10^{3}$ dynes is indicated in the right margin. The reproduction is the size of the original. 

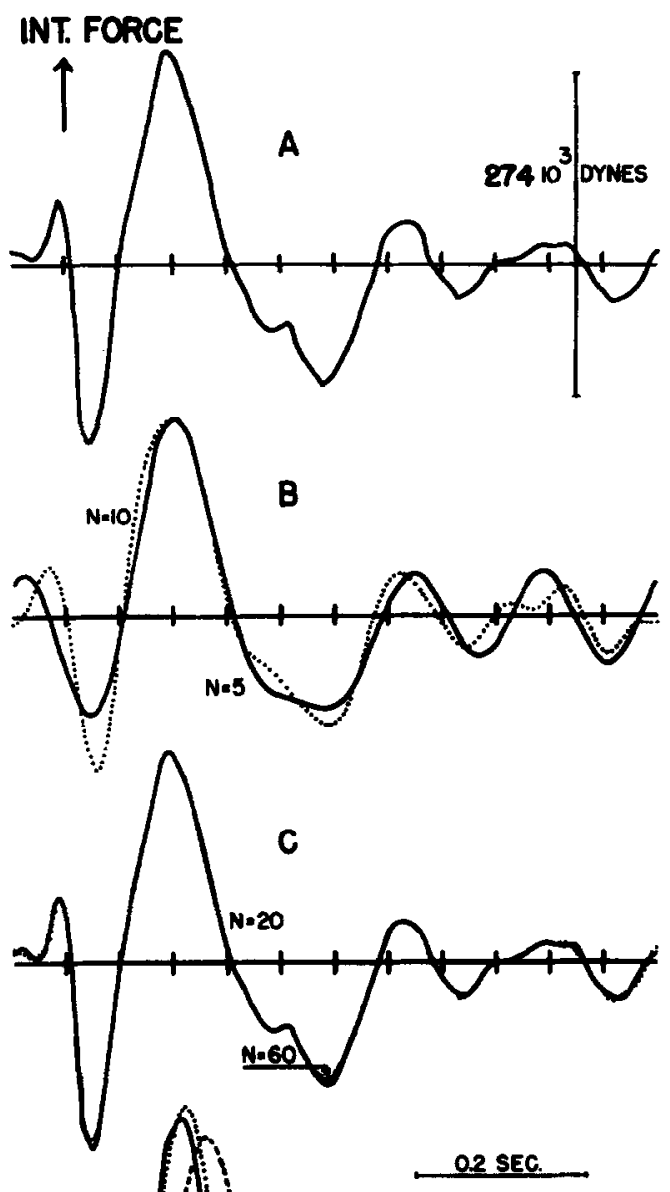

D

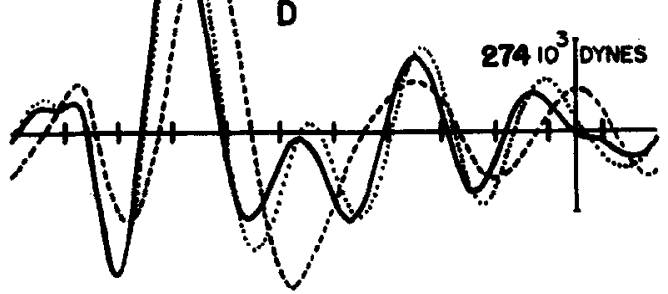

Fig. 12. $A$, Enlaryed experimental ULF ballistocardiograms (Subject B.P.). B, Synthesis of this ballistocardiogram using the first 5 and 10 Fourier harmonics. $C$, For the first 20 and all 60 harmonics. $D$, HF ballistocardiograms calculated from the curve in $A$ for 3 degrees of tightening given in Fig. 6 . (Subject loose, dashed line; tight, dotted line; very tight, solid line.) All curves are synchronous. The same calibration is valid for $A, B$, and $C$. Note the improvement in similarity in $A$ and $D$ with increasing tightness of the coupling between the subject and table.

each subject (the third complex in the top row of Figs. 10 and 11, respectively) was enlarged photographically as is shown in Figs. $12, A$ and $13, A$. After measurement, each of these curves was developed into a
Fourier series of 60 harmonics, i.e., 60 sine waves, that with the lowest frequency having the frequency indicated by the heart rate of the subject. For both ultralow-frequency ballistocardiograms the amplitude of the lower, middle, and higher harmonics is given in Fig. 14. Our findings resemble but are not exactly similar to those of Honig and von Wittern, ${ }^{8}$ for we did not find a second peak around 10 c.p.s. as high as that found by these authors.

Obviously, the lower harmonics constitute the major part of the ballistocardiograms, as is demonstrated in Figs. 12, $B$ and $13, B$, and are responsible for the general form and amplitude of the waves. The higher frequencies play a part only where notches and slurs are concerned (Figs. 12,C and 13,C).

To construct a theoretical high-frequency ballistocardiogram from measurements made on the ultralow-frequency record the computation was continued as follows. Each of the 60 harmonics was shifted in time and changed in amplitude according to information about the properties of the $\mathrm{HF}$ systems given in Fig. 6. Thus, those harmonics of the ULF record which were delivered in resonance with the movement of the body on the table were increased in amplitude, those harmonics of the ULF record higher than the resonance frequency of the body on the table were reduced, and each was shifted in time in accord with the phase shift of the system. Finally, a new curve was constructed by again adding the altered components at each instant of time. Similar theoretical curves were constructed for several degrees of tightness of attachment of the subject to the HF tables.

The results (Figs. 12,D and 13,D) show clearly that the curves thus constructed from measurements made on low-frequency ballistocardiograms bear a close resemblance in shape and amplitude to the HF ballistocardiograms (Figs. 10 and 11) sccured cxperimentally on the same subjects. Obviously, therefore, we have a clear understanding of the reason for the major points of difference between the two types of records, ${ }^{9}$ the average differences of wave height and timing shown in Fig. 7,A and $B$.

However, for reasons to be discussed, 
we were not so confident that the notching of the waves seen in the ULF, but not in the HF records could be explained completely by differences in physical properties of the two instruments, although it was clear from the computation that the higher frequency components of the ballistocardiogram were strongly attenuated by the $\mathrm{HF}$ instrument (Fig. $6, A$ ), so that the effect of high-frequency forces, notching of the waves, would be reduced in $\mathrm{HF}$ records. Before accepting this view completely, we sought to discover whether differences in movements of the body in space, so obvious to anyone who has taken

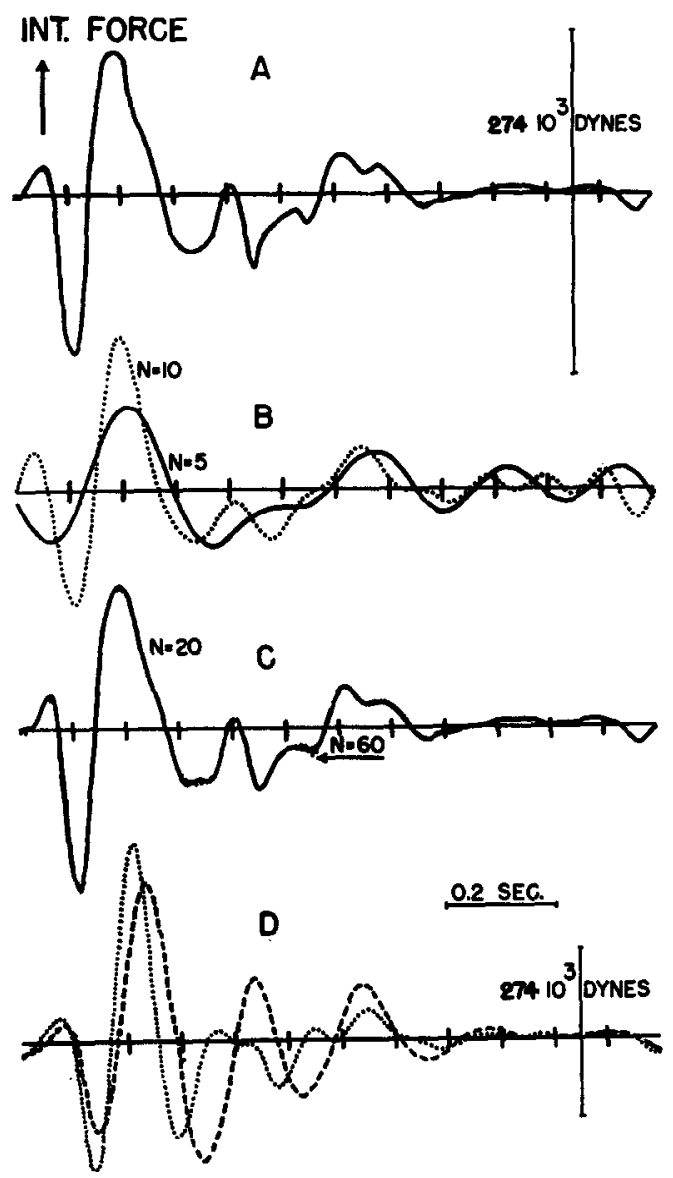

Fig. 13. $A$, Enlarged experimental ULF ballistocardiogram (Subject F.Y.E.). B, Synthesis of this ballistocardiogram using the first 5 and 10 Fourier harmonics. $C$, For the first 20 and all 60 harmonics. $D$, HF ballistocardiograms calculated from the curve in $A$ for 2 of the 3 degrees of tightening given in Fig. 6 (subject loose, dashed line; tight, dolted line). All curves are synchronous. The same calibration is valid for $A, B$, and $C$. both types of records, might not be playing a part.

Is there an error from "loose parts" moving in the body? HF and ULF records are not taken under identical conditions. When a subject is on the ULF table, the movement of the body in space is plainly visible; but when he is lying on the HF table, no movement can be seen by the naked eye. As measured by a microscope that is supported from the floor, the distance which the body moves during the respiratory cycle may be 100 times greater on the ULF than on the HF instrument. The systolic displacement of a pointer attached to the shin bar of a subject lying on the ULF instrument is about 5 times as great as that of the same subject lying on the $\mathrm{HF}$ instrument, a value which agrees with that calculated from theory. Not only does the amplitude of the systolic movement differ, but also the shape; the body's displacement when on the HF table has the pattern of the second time derivative of the body's displacement when on the ULF bed.

The body is not a solid block. ${ }^{10}$ The limbs and head move on the trunk, and many abdominal organs move with respiration. Collections of fluid are present normally in the circulation, cerebrospinal canal, gastrointestinal tract, and bladder; abnormally, they often appear in the pleura and peritoneum. If the body frame is suddenly moved forward in space, the pools of fluid and the loosely connected body parts, left behind initially because of their inertia, will be accelerated as their connections tighten; and these masses, again because of their inertia, will continue to move forward, decelerating, for a brief period after the body frame has stopped. Also, waves within the fluid masses may persist after body movement has ceased. Such movements within the body may cause trouble to one attempting to interpret the ballistocardiogram: (1) by producing secondary inertial forces which warp the record of the forces of the circulation, and (2) by interfering with the correct estimation of the circulatory forces from the product of acceleration and body mass, because the total mass, as determined by a balance, will undoubtedly be greater than the mass moving when ac- 


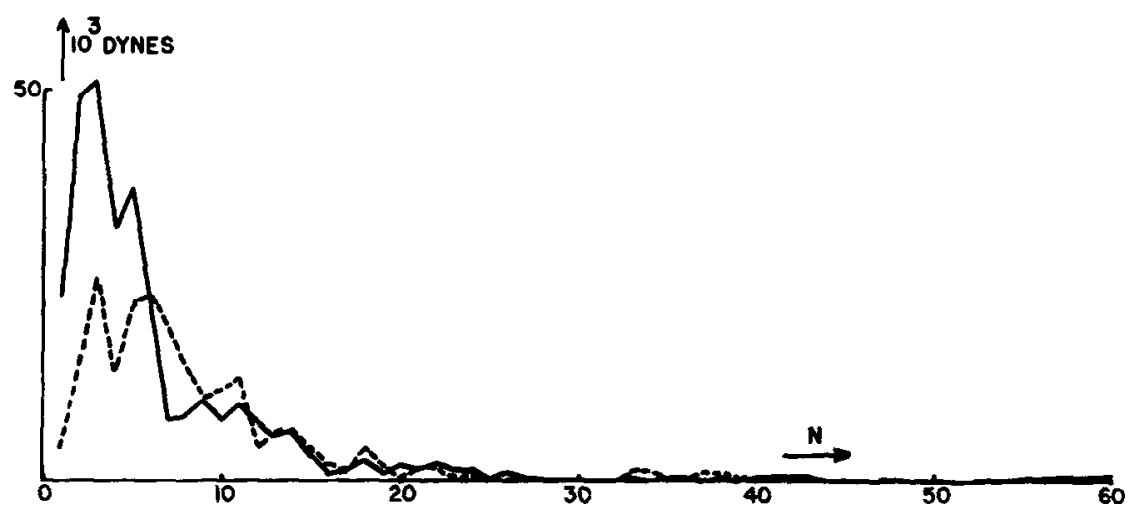

Fig. 14. The a mplitude of the Fourier components of the ULF ballistocardiograms represented in Fig. 12,A (solid line) and Fig. 13,A (dashed line).

celeration of the body frame began, if loose masses are left behind until their connections tighten. Obviously, we needed to convince ourselves that there was not a serious source of error here; hence, more knowledge both of the presence of "loose masses" and of the character of their connections was sought.

The effect of introducing a loosely connected mass. An iron block of either 5 or 10 -kilogram mass was placed on the body of 6 subjects who lay first on the HF and then on the ULF ballistocardiograph. The frequency of the block-body coupling was determined by striking the block.

The results (Figs. 15 and 16) were consistent. When the subject lay on the ULF instrument, the presence of the block distorted the record by producing notches on the waves and, sometimes, changing the height of the peaks of the waves. The position of the abnormal notches on the normal waves of the ballistocardiogram varies with the frequency of the blockbody coupling.

But when the subject lay on the HF instrument, the presence of the same block either had no effect on the record at all or caused only a slight slurring. Obviously, loose parts attached to the body of a subject whose control ULF record shows no notches give rise to notches which resemble those seen in the ULF records of certain other subjects. The question immediately arises whether there are lonse parts in the bodies of certain people which, by wobbling like the iron block when the body moves in space, produce secondary forces which distort the ULF ballistocardiograms with artifacts not related to the circulation.

We designed an experiment to answer this question. If loose parts capable of causing distortion in ballistocardiograms were present, we could demonstrate them by first applying to a subject on the ULF ballistocardiograph a force sufficient to set his body in motion, and then having that force terminate instantaneously. The continued appearance of forces in the record after the inciting force had ceased would indicate the presence of secondary forces which could be attributed to loose parts of the body which were still moving with respect to the body frame.

First, we demonstrated that, with iron blocks instead of a subject on the ULF ballistocardiograph, forces induced by tapping or by pulling on a thread until it broke did terminate almost instantly, an experiment which also indicates that there is no important source of interfering highfrequency vibrations in the table itself. Then, with a patient on the ULF instrument, the amplification was cut down until the ballistocardiogram was just visible, and similar forces were applied to the subject's body. In 200 experiments on 30 subjects the transient force was applied by tapping the head or the feet. In 30 other experiments on 6 subjects a thread was tied about the subject's neck or feet and given a jerk so sharp that it broke. In these latter experiments, rupture of the thread often produced a burst of highfrequency vibrations which, also present 
when the experiment was performed with iron bars instead of a subject, were plainly artifacts connected with the breaking of the thread and not due to the movements of parts of the body. Otherwise, the results secured in the two series were very similar, and typical examples are shown in Fig. 17.

Two features are seen in almost every record: first, a slow component returns the record to the base line, 0.08 to 0.12 second after the peak of the transient; and second, superimposed on this slow component are more rapid vibrations, not in a single frequency in any subject but which, when measured roughly, ranged from 10 to 20 cycles per second in different subjects. Occasionally, as in $A$ and $D$ of Fig. 17, one of these components is present without the other. Whatever the combination the effect is very brief, usually over in about 0.2 second.

Thus, through the use of inciting forces many times larger than those which are the genesis of ballistocardiograms, we have demonstrated small secondary forces of brief duration which cannot be attributed to the circulation. If the much smaller inciting forces which are the genesis of the ballistocardiogram brought out secondary forces proportionate in size, these noncirculatory forces could have an influence on the ULF record, and the production of notches would be the most obvious effect. Thus, studies of the same problem from the theoretical viewpoint also seemed to be worth while, although one could hope to explore only a few of the many possibilities.

Theoretical studies on the effect of loose masses within the body. In order to get a better quantitative appreciation of the influence of a loosely coupled mass on the recorded ballistocardiogram, a number of cases were worked out quantitatively, making use of the digital computer of the University of Utrecht and of a suitable analogue computer. Since little knowledge is available in regard to the numerical values that should be assumed in these calculations, a fairly wide range was chosen, namely: (a) for the "loose" mass: $2,4,8$, and $16 \mathrm{Kg}$.; (b) for its coupling to the remainder of the body: a resonance frequency of 5, 10, and 20 c.p.s.; (c) for its damping: 40 and 100 per cent of the critical value.
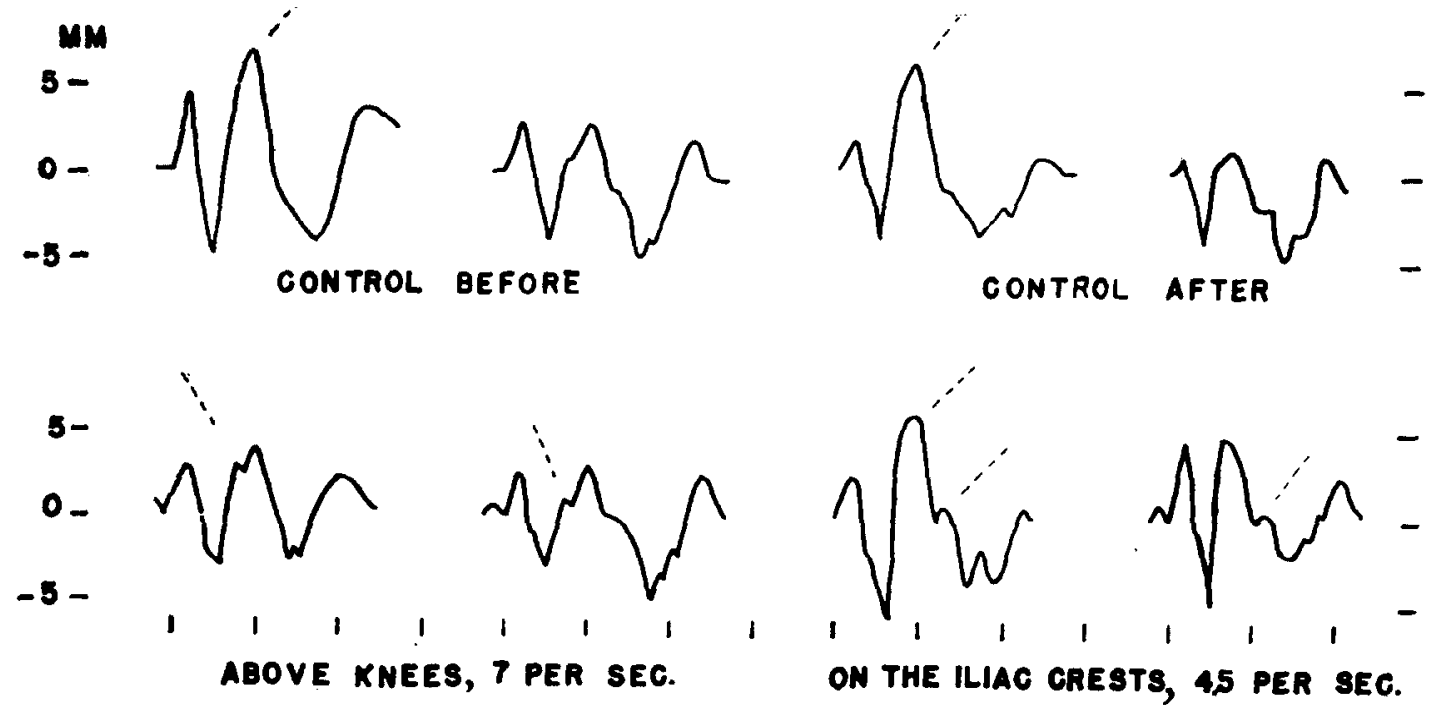

Fig. 15. Effect on the ULF ballistocardiogram of the experimental introduction of a "loose" mass. Drawings of typical large and small complexes of the respiratory cycle of the record of a healthy young man. $T_{p p e r}$ left: Control record before the experiment. Lower left: Record after the introduction of a 10-Kg. iron block placed on the skin above the knees, where it had a coupling with the body whose frequency was $7 /$ sec. Lower right: Record after the block had been removed to the lower abdomen, where it rested on the skin over the iliac crests. Here the frequency of its coupling was $4.5 / \mathrm{sec}$. Upper right: Control record after removal of the block. Note the appearance of notches after the introduction of the "loose" mass. The position of these notches on the record changes when the frequency of the block-body coupling changes. 


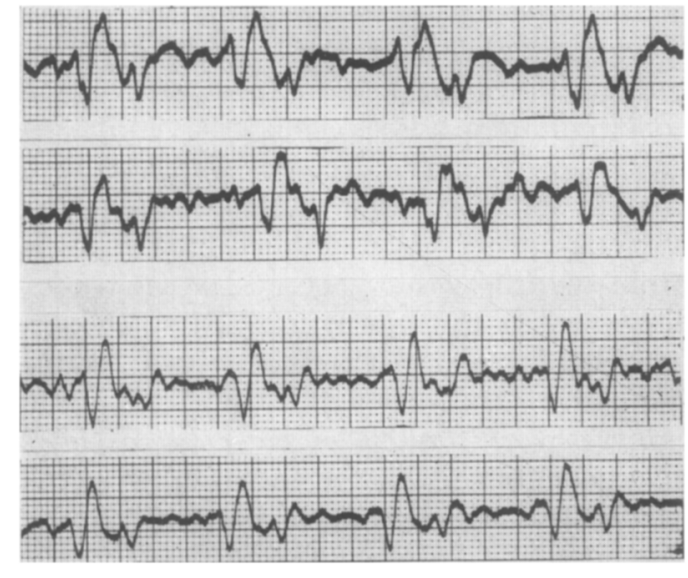

Fig. 16. Effect on the ballistocardiogram of the movement of a "loose" mass: a $10-\mathrm{Kg}$, iron block lying on the subject. Top: Control ULF ballistocardiogram of a normal subject. Second: Same subject, with block placed above his knees. Frequency of block-body coupling $5 / \mathrm{sec}$. Note the notching of the ULF record which results. Third: HF ballistocardiogram of the same subject. Bottom: Same subject with the same block placed above his knees. Frequency of coupling $5 / \mathrm{sec}$. No notching of the HF record results.

Each combination of three figures, one being taken for each heading, defines a specific problem. For a great number of combinations, frequency characteristics (both amplitude and phase) were computed by Miss van Hoorn ${ }^{11}$ for the $\mathrm{HF}$ and ULF instruments described in this paper. A few of the results are reproduced as Figs. 18 and 19.*

\section{Discussion}

In the theory of the ballistocardiogram, four situations have been envisioned: in the first approximation the body is considered to be a solid unit with its support ${ }^{5}$; in the second, the body is considered to be a solid block with contact with its support through a viscoelastic coupling ${ }^{3,5,7}$; in the third, we envision the circulatory system as distinct from the body frame and connected to it by a viscoelastic coupling; and in the fourth, we regard the frame as divided into two or more parts, each connected with its support. ${ }^{5,12} \mathrm{~A}$ still closer

*A full account of the results may be obtained by writing to the Department of Medical Physics, Physics Laboratory, Bylhouwerstraat 6, Utrecht, referring to Internal Report $\mathrm{V}$ 1682. A mimeographed copy of the full rcport is available on request. approximation of reality would be a combination of the last two. The first three approximations have been considered bcfore; the second and fourth are treated in this paper (Figs. 6 and 18).

Problems concerned with the attachment of the parts of the body to one another have seldom come up in medicine or physiology, but they were studied by Wilson, Cunningham and Griswold, ${ }^{10}$ who shook the body at various frequencies and concluded that it did not move as a unit. If the parts of the body were free to move within the limits imposed by elastic couplings of known properties, one could calculate the effect we seek. But there is doubt whether one can safely assume that these properties are linear. Thus, the liver moves a centimeter or two during each respiration, and its attachment to the body frame is not solely through the ligaments which limit its motion, but, also, when the patient is recumbent, through the friction of its weight pressing against the spine and ribs. If the force required to overcome this friction is not linear, the motion imparted to the liver by movement of the body frame in space cannot, at present, be calculated with confidence. But one could demonstrate it by experi-

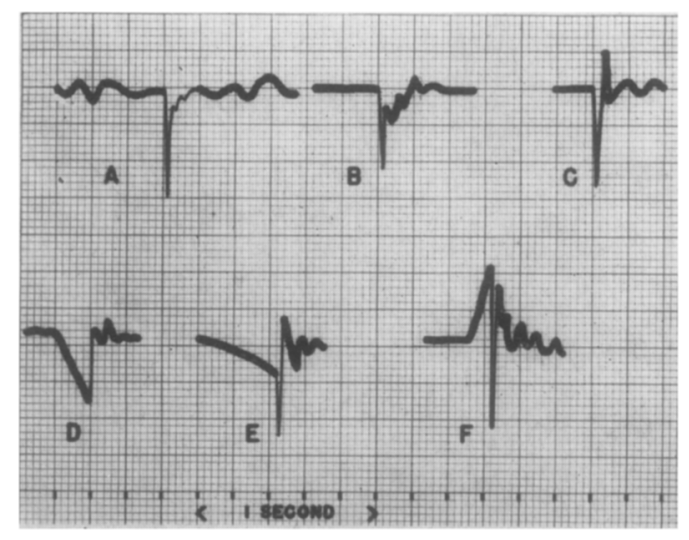

Fig. 17. Forces registered in ULF records after a transient force has been applied and withdrawn as rapidly as possible. Top row: Typical examples of records secured after the subject was tapped on the head. Bottom row: Typical examples of records obtained when a thread attached around the chest, neck, or feet was pulled until it broke. Note the secondary vibrations set up and the slow return to the base line often seen. The record was attenuated until the ballistocardingram was hardly detectable. 
ment, and our results indicate that even when the experimental inciting forces are many times larger than those which occur naturally during the taking of the ballistocardiograms, the secondary forces called forth are small. So, despite our doubts, the results of our experiments and of our calculations agree with each other, and with the results secured by Wilson, Cunningham and Griswold ${ }^{10}$ when the body was shaken. One must conclude that movement of loose parts of the body and in the fluid pools has little effect on the ballistocardiogram. But this does not mean that such effects are negligible.

From our theoretical studies, one can draw four conclusions. (a) The HF force tracing is distorted by movement of the body on the table, although it should be noted that because of recent improvements this movement is much smaller and the distortion caused is much less than that sometimes seen on records secured by older instruments with high natural frequency. (b) The HF force tracing is little affected by the presence of "loose" masses connected with the hody. (c) The ULF force tracing is distorted very little by motion between the body and its support. (d) Since the ULF acceleration tracing also represents the higher frequency components, it is sensitive to effects caused by the relative motion of parts of the body. Notching of the curve might be enhanced by this property.

From the calculations and the results of the experiments it is evident that records taken with the ULF instruments provide high-frequency information of a type which is absent in the HF record, and we are confronted with the question of the physiologic origin and the clinical value of this new information. It is far from certain that all the slurs and notches so commonly seen in ULF ballistocardiograms have their origin in the circulation, and, if not, a better estimate of circulatory abnormalities might be made if they were not recorded.

The chief argument in favor of a circulatory origin for the notches so often seen in ULF record lies in their apparent movement with respiration. Thus, if located in the H-I or I-J segment, such notches commonly move up and down the seg- ment with the phases of respiration. This movement suggests a physiologic origin secondary to differences in the strength of cardiac contraction caused by the differences in cardiac filling which follow the changing filling pressures of the respiratory cycle.

Thus, such notches have been interpreted as indicating asynchronism of the forces of the two sides of the heart. ${ }^{15}$ This is a reasonable explanation supported by other physiologic evidence. Indeed, notches on the $J$ wave have been produced experimentally by simulating asynchronous cardiac ejection in cadavers. ${ }^{13}$ But several observations provide an alternative explanation, although they certainly do not disprove this physiologic interpretation. First, careful measurement shows that in many instances the notches, when moving up and down with the respiratory cycle, maintain their position in time; it is changes in the slope of the segments which make them move toward or away from the base line. Second, when the introduction of a loosely coupled mass produces notches in the UI.F record which are clearly not due to the circulation, these notches also appear to move with respiration. Evidently, the fact that a notch changes position with respiration is not proof of its circulatory origin. Third, when one sees systolic notching in the ULF record, as in $C, E$, and $G$ of Fig. 9, careful inspection sometimes discloses similar highfrequency phenomena in the diastolic parts as well. Some notches occur so late in diastole that they are unlikely to have a cardiac origin, and when such notches are associated with systolic notches, one suspects that both may have a similar origin outside the circulation.

We have carefully searched the clinical data to see whether those subjects with systolic notches in the ULF record, but not in the $\mathrm{HF}$ record, showed any clinical similarities which would aid in interpreting the finding. But we have not yet found any. Systolic notching occurs in the ULF records of many young adults who appear to be in good health. If such notches are evidence of cardiac abnormality, it is of a new type which occurs frequently in apparently healthy persons, and which is not necessarily related to any of the 

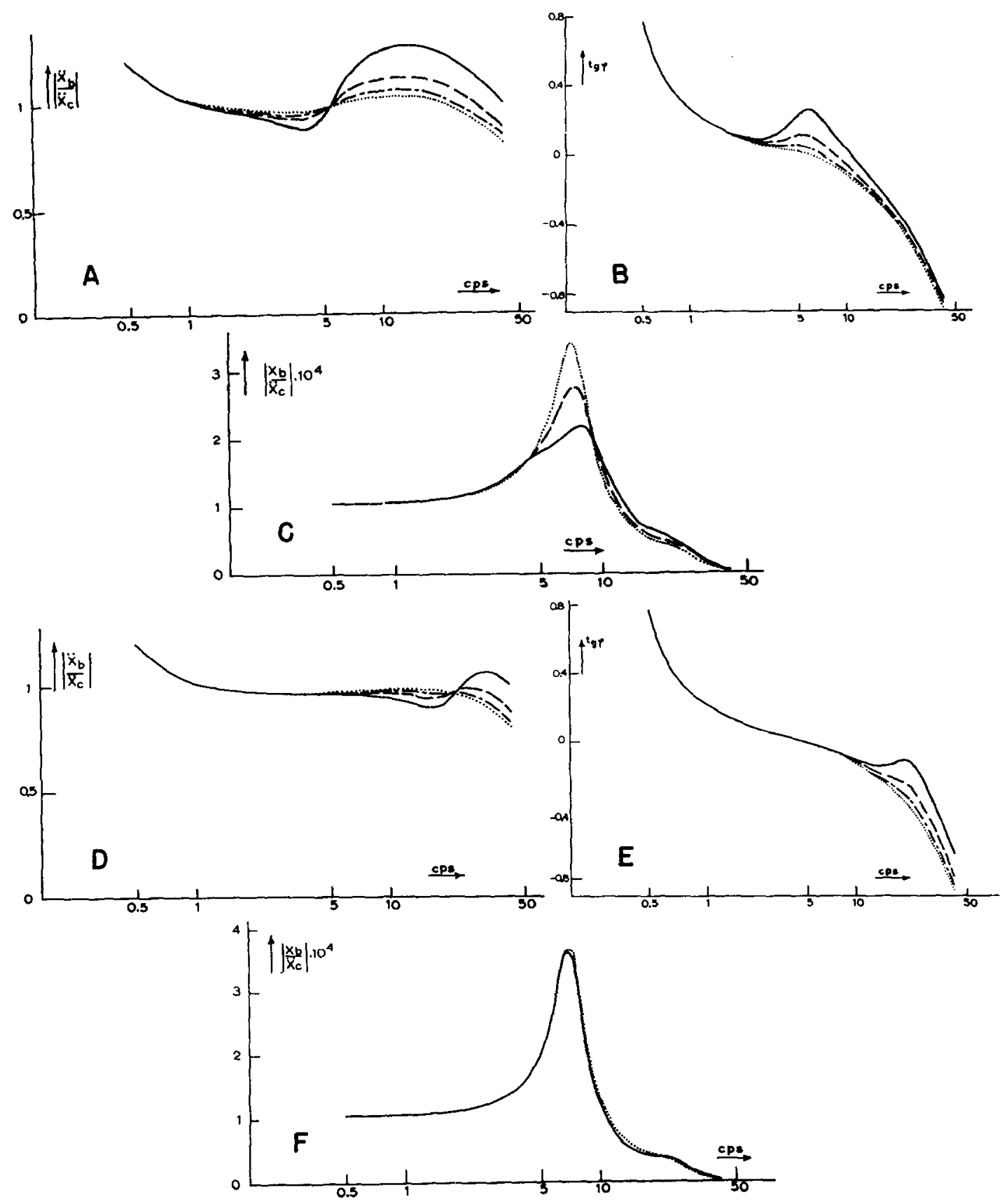

Fig. 18. $A$, Amplitude characteristics of the ULF instrument, taking into account the coupling between body and support, and that between the body and a loose part of it, of (a) $2 \mathrm{Kg}$. (dotted line), (b) $4 \mathrm{Kg}$. (dashed-dot line), (c) $8 \mathrm{Kg}$. (dashed line), and (d) $16 \mathrm{Kg}$. (solid line). The natural frequency of the loose part is taken as 5 c.p.s., and its damping is 40 per cent of the critical value. $B$, Phase characteristics for the same cases. $C$, Amplitude characteristics of the HF instrument for cases a, c, and $\mathrm{d}$ in $A . D$ and $E$, Same as $A$ and $B$, except that the natural frequency of the loose mass is 20 instead of 5 c.p.s. $F$, Same as $C$, except that the natural frequency of the loose mass is 20 instead of 5 c.p.s. (cases a and $d$ only). The amplitude of the internal acceleration of the center of gravity is denoted $\ddot{x}_{c}$, the amplitude of the acceleration of the ULF instrument is $\ddot{x}_{b}$, that of the displacement of the HF instrument is $x_{b}$. The phase angle between drive and response is $\varphi$. 

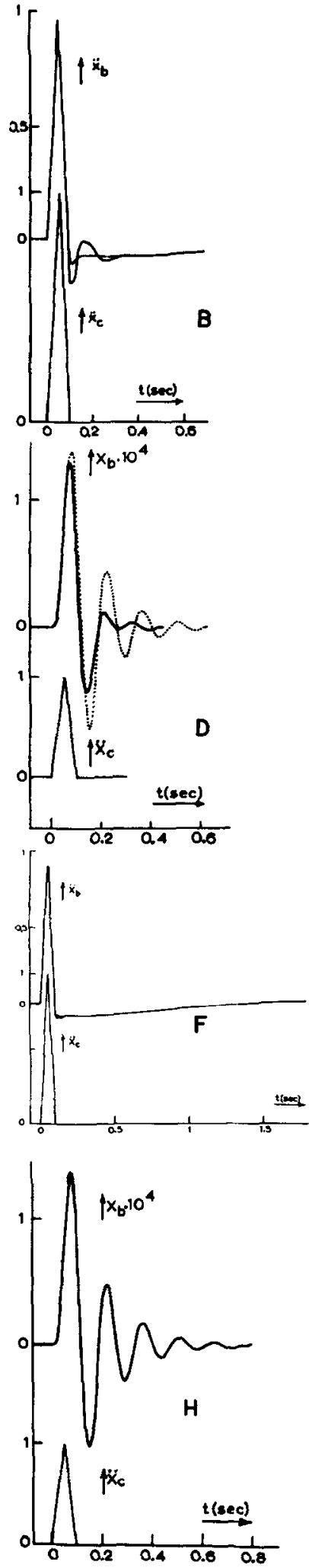

Fig. 19. (For legend see opposite column.) types of heart disease with which we are familiar. In contrast, abnormalities in the low-frequency phenomena shown by the Fourier analysis to be the dominant components of ballistocardiograms, and recorded by both $\mathrm{HF}$ and ULF instruments, are readily related to cardiac disease as we know it from other sources, and to the effect of treatment upon it. While the search should certainly be continued, we have as yet found no evidence that important clinical information is contained in the notches and slurs recorded solely by the ULF instruments.

Similarities of $H F$ and $U L F$ records. By spending so much time and effort in an attempt to understand the differences found between the two types of ballistocardiograms, we run the risk of exaggerating their importance in the reader's mind. For most practical purposes these differences are of little moment. Of far greater importance is the finding that the ULF and HF methods, which are quite different methods of detecting forces, are in good quantitative agreement about so many aspects of the forces of the circulation. The agreement in contour, depth, and duration of the $\mathrm{H}$ and I waves of the two types of records is so close that for practical purposes the results are identical. In our early $H F$ records the terminal complex (the $L, M$, and $N$ waves) was often overwhelmed by aftervibrations, but with the recent improvements it usually appears as clearly as it does in ULF records. All this is strong evidence that we are getting a reasonably true record of the forces of the circulation by both methods. The sole important difference lies in the $J$ wave, which, although of nearly similar area in the two records, is consistently taller and narrower in $\mathrm{HF}$ records. If one bases his judgment on

Fig. 19. Response of the UI.F instruments to a triangular shaped internal acceleration of the center of gravity $\ddot{x}_{c}$ (proportional to internal force) (boltom in $B, D, F$, and $H), B_{f}(t o p)$ The acceleration $\ddot{x}_{b}$ of the ULF instrument for cases a and $\mathrm{d}$ of Fig. 18, $\mathrm{A}$ and $B . D,(t o p)$ The displacement $x_{\mathrm{b}}$ of the HF instrument for the same cases. $F$, (top) The acceleration $\ddot{x}_{b}$ of the ULF instrument for cases a and $\mathrm{d}$ of Fig. $18, D$ and $E . \quad H$, (top) The displacement $x_{\mathrm{b}}$ of the $\mathrm{HF}$ instrument for the same cases. 
area rather than altitude of the wave, the two methods give almost identical results.

The finding of striking similarity between corresponding wave areas in the two methods is again in agreement with theoretical considerations, for the physical properties of the two systems indicate that there is little distortion in the lower frequency harmonics of either system. Therefore, records of the velocity of the body's center of gravity taken by the two instruments will be more similar than records of its acceleration, the subject of this study. For the same reason, records of the displacement of the body's center of gravity, the second integral of the HF records described in this paper, and the ULF records when displacement is recorded would be almost identical. It is in the lower harmonics that the important clinical information has been identified.

Chiefly because of the difference in J-wave amplitude, the over-all amplitudethe vertical distance betwcen the tips of the $\mathrm{I}$ and $\mathrm{J}$ waves - is larger in $\mathrm{HF}$ than in ULF records. This difference in amplitude is very constant; in 50 consecutive subjects tested by both methods the correlation between the two amplitudes was very strong, $r=0.87$. The test-retest correlation for 53 subjects tested on our original $\mathrm{HF}$ instrument was $0.91,{ }^{14}$ an almost identical value. Therefore, arrangement of the subjects in the order of the amplitude of their HF or ULF records would yield two series not significantly different in arrangement, and, although the normal standards for amplitude would be different in absolute value, patients with abnormal amplitudes could be as readily detected by one method as by the other.

Which is the better method? No simple answer can be given to this question. The ULF is a beautiful method, and its chief advantage is obvious, i.e., movement between body and table is avoided. By our present setup we cdil secure records of the displacement and velocity of the body's center of gravity as well as the force record discussed in this paper. On the other hand, the apparatus is at present fixed in position in one room, and it is more fragile than the HF table. Technicians find it more difficult to calibrate and to operate. Acute experiments on subjects are more difficult to perform on the ULF instrument; unless care is taken, tension in tubes and wires attached to the subject may restrict the movement of the table.

In contrast, the HF instrument is so strongly constructed that breakage and mechanical difficulties almost never occur. The subjects must be carefully made tight on the table, and there is a source of error inherent in this, since differences in the degree of tightness cause small differences in the record. But even when the subjects are maximally tight, the HF record will not show high-frequency phenomena as does the ULF record. The HF instrument requires a larger amplifier than does the ULF instrument. Although the electronic equipment in use at present permits only the force record, its integrals could be readily secured by additional equipment. Our routine HF force calibration is both easier and more accurate than the best we have been able to obtain on the ULF instrument. Our most recent instrument permits records with the subject tilted as well as prone, a great advantage in the study of dyspneic patients who cannot lie flat. Experiments are easily performed on subjects lying on the $\mathrm{HF}$ table; the attachment of tubes and wires to the subject, and the disturbance of taking blood pressure by the auscultatory method make no difference at all. As an instrument for routine clinical testing to be run by hospital technicians the practical advantages of the $\mathrm{HF}$ over the present ULF system are still considerable.

If high-frequency phenomena over 10 per second prove to be of importance in the diagnosis of cardiac disease, or in the estimation of the effects of therapy, the ULF instrument will be the only one to use. But it must be pointed out that this prolonged clinical study has produced no evidence that important clinical information lies solely in the range in which the ULF record is clearly superior.

\section{Conclusion}

An improved form of high-frequency ballistocardiograph, which can be tilted, is described. A new ultralow-frequency ballistocardiograph is also described. 
A large series of patients and healthy persons has been tested on both instruments. There are two main differences between the records of the cardiac and circulatory forces obtained by the two instruments: (1) most large waves of the HF records are taller and narrower than those of the ULF records; (2) notches and slurs often appear in the ULF records which have no counterpart in $\mathrm{HF}$ records.

By a mathematical analysis of the physical properties of the two instruments, and by some assumptions in regard to the physical properties of the connections of various parts of the body, these differences could be accounted for theoretically.

The apparatus required for the $\mathrm{HF}$ method is more rugged and simpler to use than that of the ULF method, but the movement of the subject on the table is a serious drawback. This drawback has been reduced by modern techniques, but the difficulty has not been altogether mastered.

The ULF method, although somewhat more difficult for technicians to calibrate and operate, avoids the difficulty due to movement between subject and table. But, since all parts of the body are not tightly connected with one another, this record is more subject to distortion from secondary inertial forces which arise from relative movement of parts of the body and in fluid pools within it. This difficulty does not seem to produce more than a minor effect on this record in the situations which we have examined.

Judged from the physical properties of the two systems, HF and ULF records of the velocity of the movement of the body's center of gravity, the integrals of the records described here, would be more similar than their force records. For the same reason, HF and ULF records of displacement of the body's center of gravity, the second integrals of the records described here, would be almost identical.

The similarities of the two force records are much more striking than the differences. The terminal complexes are well shown by both methods. The gross abnormalities in form and amplitude, on which clinicians should rely for the detection of cardiac or circulatory abnormality, are clearly shown by both methods.
The major part of the work was conducted when the authors worked together in Philadelphia, but many of the calculations were completed by the junior author after he had returned to Utrecht. We are greatly indebted to Miss Willy van Hoorn, who played an important part in the calculations made in Utrecht, and to Dr. A. van der Sluis, who assisted in the operation of the "Zebra" digital computer of the University of Utrecht. We are also indebted to Mrs. Gertrude Noordergraaf for technical assistance in taking and evaluating the ballistocardiograms made on patients and healthy persons in Philadelphia, and to Mrs. Maxine Rockoff, who wrote the program to handle the data given to the Univac digital computer of the University of Pennsylvania.

\section{REFERENCES}

1. Starr, I., Rawson, A. J., Schroeder, H. A., and Joseph, H. R.: Studies on the estimation of cardiac output in man, and of abnormalities of cardiac function, from the heart's recoil and the blood's impacts; the ballistocardiogram, Am. J. Physiol. 127:1, 1939.

2. Mayock, R. L., Koop, C. E., Riegel, C., Kough, N. T,, and Starr, I.: Convalescence from surgical procedures, Am. J. M. Sc. 212:591, 1946.

3. Von Wittern, W. W.: Ballistocardiography with elimination of the influence of the vibration properties of the body. Am. Heart J. 46:705, 1953.

4. Talbot, S. A., and Harrison, W. K.: Dynamic comparison of current ballistocardiographic methods. Parts 1-3, Circulation 12:577, 845, and $1022,1955$.

5. Noordergraaf, A.: Physical basis of ballistocardiography, Thesis, University of Utrecht, 1956.

6. Rappaport, M. B.: Displacement, velocity and acceleration ballistocardiograms as registered with an undamped bed of ultra-low natural frequency. II. Instrumental considerations, Am. Heart J. 52:643, 1956.

7. Burger, H. C., Noordergraaf, A., Korsten, J. J. M., and Ullersma, P.: Physical basis of ballistocardiography. IV. The relative movement of subject and ballistocardiograph, АM. HeART J. 52:653, 1956.

8. Honig, C. R., and von Wittern, W. W.: Harmonic analysis of the ballistocardiogram, Proc. Soc. Exper. Biol. \& Med. $97: 709,1958$.

9. Deuchar, D. C., Talbot, S. A., and Scarborough, W. R.: Somc obscrvations on the rclation of the high-frequency bed ballistocardiogram to that obtained from an aperiodic bed, Circulation $11: 228,1955$.

10. Wilson, G. P., Cunningham, D. M., and Griswold, H. E.: Experimental response of the human body to a known periodic force as a measure of ballistocardiographic fidelity, Circulation 15:280, 1957.

11. Van Hoorn, W.: The distortion of the force tracing as recorded by the improved highfrequency (Starr) and by the ultralow-frequency ballistocardiograph caused by "loose" organs, 
Internal Report of the Physics Laboratory, University of Utrecht, V 1682, 1961.

12. Burger, H. C., Noordergraaf, A., and Kamps, H. J. L.: Physical basis of ballistocardiography. $\mathrm{V}$. The distortion of the ballistocardiogram caused by the movement of the heart inside the body, Am. Heart J. 53:907, 1957.

13. Starr, I.: Relation of the ballistocardiogram to cardiac function, Anı. J. Cardiol. 2:737, 1958.

14. Tanner, J. M.: Intercorrelation between cardio- vascular variables in healthy men and the relation of physique to these and other variabics, Am. J. M. Sc. 214:233, 1947.

15. Reeves, T. J., Hefner, L. L., Jones, W. B., and Sparks, J. E.: Wide frequency range force ballistocardiogram. Its correlation with cardiovascular dynamics, Circulation 16:43, 1957

16. Gamble, W.: A simple mechanical calibrator for the ultralow-frequency ballistocardiogtaphic bet, Ant. J. M. Sc. 234:240, 1957. 